\title{
Quem quer ser professor? Atratividade, seleção e formação docente no Brasil1
}

\author{
PAULA LOUZANO* \\ VALÉRIA ROCHA** \\ GABRIELA MIRANDA MORICONI*** \\ ROMUALDO PORTELA DE OLIVEIRA ${ }^{* * * *}$
}

\section{RESUMO}

Neste trabalho, buscou-se identificar os problemas que o Brasil encontra para selecionar e contratar bons professores. Há poucos incentivos financeiros para os melhores alunos do ensino médio se tornarem docentes. Além disso, o Brasil atrai indivíduos com baixo rendimento acadêmico e com perfil socioeconômico mais baixo para cursos de formação de professores. Um estudo empírico buscou analisar a qualidade da formaçáo inicial oferecida a esses futuros professores, utilizando os dados do Enade. Ele revelou que os cursos de Pedagogia das instituiçóes públicas são, na média, melhores que os das instituiçóes privadas, mesmo

${ }^{1}$ Este estudo, financiado pela Fundaçáo Lemann e pelo Instituto Futuro Brasil (IFB), foi apresentado no seminário $O$ Professor visto como um profissional: captação, formação e retenção de talentos realizado no Insper (antigo IBMEC), em julho de 2008.

*Pesquisadora da Fundação Lemann (paula.louzano@fundacaolemann.org.br).

** Doutoranda em educação pela Universidade de Harvard (valeria_rocha@mail.harvard.edu). *** Coordenadora-Geral de Instrumentos e Medidas Educacionais, Inep/MEC (gabriela. moriconi@inep.gov.br).

**** Professor Titular da Faculdade de Educação da Universidade Sáo Paulo (USP) (romualdo@usp.br). 
quando levamos em consideração o contexto socioeconômico dos alunos desses cursos. No entanto, essa vantagem desaparece quando se considera a experiência prévia na docência. Entre os graduados de Pedagogia que já deram aulas ou já são professores - dois terços dos alunos náo se observam diferenças significativas no resultado Enade entre os alunos de instituiçōes públicas e privadas.

Palavras-chave: Magistério, Salário, Formação de professores, Análise quantitativa, Educação continuada.

\section{RESUMEN}

En este trabajo se buscó identificar los problemas que Brasil encuentra para seleccionar y contratar buenos profesores. Hay pocos incentivos financieros para que los mejores alumnos de la enseñanza media se conviertan en docentes. Además, en Brasil, los cursos de formación de profesores atraen personas con bajo rendimiento académico y con un perfil socioeconómico más bajo. Un estudio empírico intentó analizar la calidad de la formación inicial ofrecida a los futuros profesores utilizando los datos del Enade. El estudio reveló que los cursos de pedagogía de las instituciones públicas son, en promedio, mejores que los de instituciones privadas, incluso cuando se tuvo en cuenta el contexto socioeconómico de los alumnos de esos cursos. Sin embargo, esa ventaja desaparece cuando se considera la experiencia previa en la docencia. No se observan diferencias significativas en el resultado del Enade entre los alumnos de instituciones públicas y privadas, graduados en pedagogía que ya han dado clases o que ya son profesores - dos tercios de los alumnos.

Palabras clave: Magisterio, Salarios, Formación de profesores, Análisis cuantitativo, Educación continuada.

\section{ABSTRACT}

In this study we sought to identify Brazil's problems in selecting and hiring good teachers. There are few financial incentives for the best high school students to become teachers. In addition, Brazil's teacher training courses attract individuals with a low academic performance and lower socioeconomic status. An empirical study attempted to examine the quality of training provided to these future teachers using data from Enade. It revealed that Pedagogy courses in public institutions are, on average, better than those at private institutions, even when taking into account the socioeconomic background of students in these courses. However, this advantage disappears when one considers previous teaching experience. Among Pedagogy graduates who have taught classes or are already teachers - two thirds of the students - no significant differences were observed in the Enade results between students from public and private institutions.

Keywords: Teaching, Salary, Teacher training, Quantitative analysis, Continuing education. 


\section{INTRODUÇÃO}

Segundo o relatório publicado pela consultoria McKinsey How the world's best performing schools systems come out on top (Como os sistemas escolares com melhor desempenho no mundo chegam ao topo), três ideias principais resumem o bom desempenho dos melhores países no Programa para Avaliação Internacional de Alunos (PISA ${ }^{2}$, no inglês) da Organização para a Cooperação e o Desenvolvimento Econômico (OCDE): (a) esses países são capazes de atrair os estudantes de ensino médio com melhor desempenho para a carreira docente; (b) fornecem-lhes uma formaçáo para o magistério de alta qualidade, e (c) asseguram que todas as crianças aprendam.

Isso coloca a qualidade do professor no centro do debate sobre política educacional. De fato, estudos mostram que a qualidade dos professores é um dos mais importantes preditores do desempenho acadêmico dos estudantes (Rivkin, Hanushek e Kain, 2005). Sanders e Rivers (1996) constataram que alunos com capacidades e níveis iniciais de desempenho comparáveis podem ter resultados acadêmicos diferentes, conforme a sequência de professores que lhes são atribuídos em dois anos consecutivos. Em 2000, Hammond (2000) analisou os estudos quantitativos e qualitativos que abordam a relação entre a qualidade dos professores e o desempenho dos alunos nos Estados Unidos. A pesquisadora descobriu que a formação e certificação de professores têm forte correlação com o desempenho dos alunos. Realmente, o relatório da McKinsey mostra que sistemas de alto desempenho têm professores eficazes, porque além de conseguirem atrair os mais capazes para a carreira docente, a entrada em cursos de formação de professores é altamente seletiva, os processos para selecionar os candidatos para a carreira docente são bastante eficazes, e o salário inicial é alto. Por exemplo, a Finlândia, que tem obtido o melhor desempenho nas avaliaçóes do PISA desde 2000, seleciona seus professores dentre os $10 \%$ melhores alunos das universidades. A Inglaterra, embora não esteja entre os 10 primeiros colocados no PISA, melhorou sensivelmente a qualidade de sua educaçáo nos últimos dez anos, investindo pesadamente na atratividade da carreira docente e na formação de seus professores.

Como o Brasil está atraindo, selecionando e formando seus professores? Como esses processos se comparam aos dos países de alto desempenho? Este trabalho tenta

\footnotetext{
${ }^{2}$ PISA é uma avaliaçăo internacional padronizada desenvolvida conjuntamente pelos países participantes e administrada a alunos de 15 anos de idade. A pesquisa foi realizada em 43 países na primeira avaliação em 2000, em 41 países na segunda avaliação em 2003, em 57 países na terceira avaliação em 2006, e 65 países participaram da quarta avaliação em 2009.
} 
responder a essas perguntas, em duas seçōes. A primeira analisa a atratividade da carreira docente no Brasil. A segunda se debruça sobre a seleçáo e formação dos professores de ensino fundamental no país.

\section{COMO SÃo ATRAÍDOS E SELECIONADOS OS PROFESSORES NO BRASIL Quem são os professores brasileiros?}

Atualmente, existem 840 mil professores do ensino fundamental lecionando da $1^{\text {a }}$ à $4^{\text {a }}$ séries no Brasil. Entre 1991 e 2006, o Brasil ganhou em média 4.500 novos professores de ensino fundamental por ano. Esse aumento no número de docentes do ensino fundamental se deve principalmente ao incremento no número de matrículas deste nível de ensino na última década. Hoje há praticamente acesso universal ao ensino fundamental no Brasil. A figura 1 mostra a evolução do número de professores do ensino fundamental no País ${ }^{3}$, entre 1991 e 2006.

Figura 1 - Evolução do número de professores do ensino fundamental no Brasil (1991-2006)

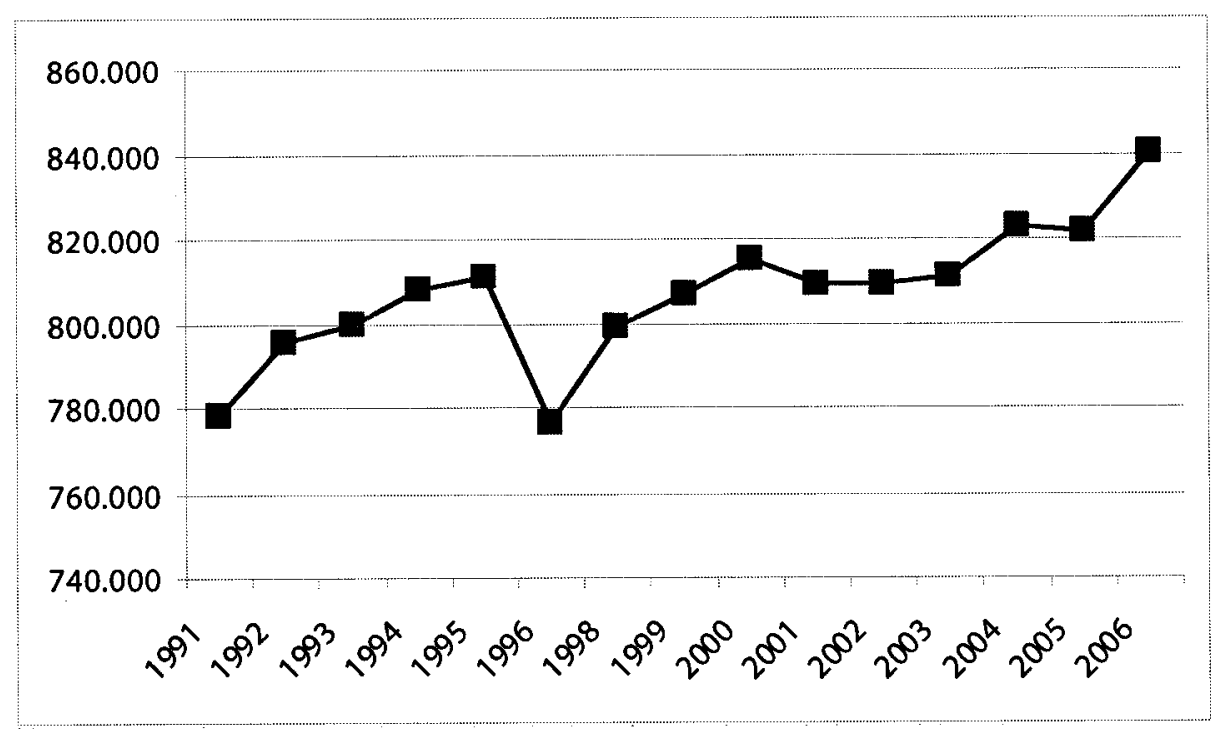

Fonte: Censo Escolar, Inep/MEC.

${ }^{3}$ A partir de 1996, houve uma mudança no processo de coleta de dados, o que explica as diferenças significativas entre 1995 e 1996, bem como uma lacuna no ano de 1997. 
A mudança na legislação educacional (LDB), em 1996, que estabelecia que todos os professores do ensino fundamental tivessem formaçáo universitária, levou a um aumento significativo no número de professores com nível superior no País. A figura 2 mostra a distribuição dos professores por nível de formação nos últimos 15 anos. Em 1991 , cerca de $20 \%$ dos docentes tinham formação superior. Em 2006, 60\% tinham obtido um diploma universitário e pouco menos de $40 \%$ dos professores tinham apenas o diploma de ensino médio. Professores sem diploma eram quase inexistentes.

Figura 2 - Distribuição de professores por nível de escolaridade no Brasil (1991-2006)

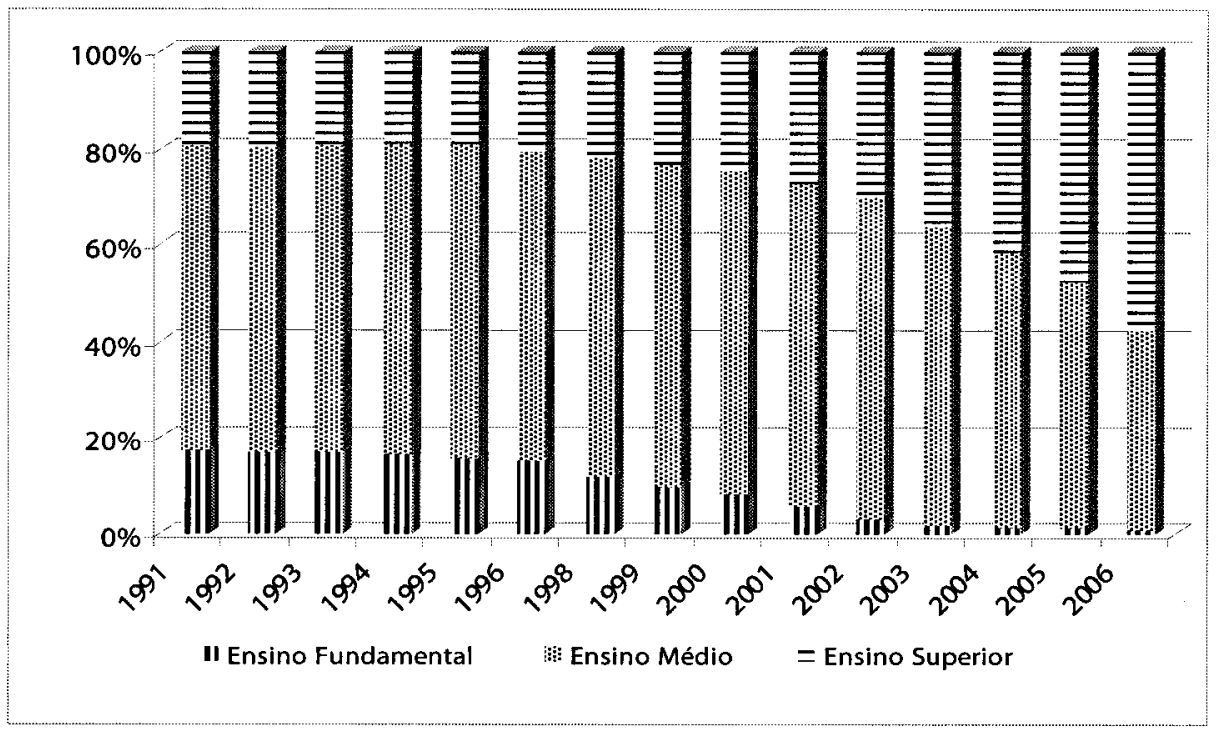

Fonte: Censo Escolar, Inep/MEC.

Conforme se observa na tabela 1, o percentual de professores por nível de escolaridade não está distribuído de forma homogênea entre as regióes. Em 1996, cerca de um terço dos professores do ensino fundamental nas regióes Norte e Nordeste tinha menos do que o ensino médio. No entanto, em 2006, esses professores eram a minoria (cerca de 2\%). Simultaneamente, o número de universitários formados aumentou significativamente no Norte e Nordeste, passando de $3 \%$ e $8 \%$, respectivamente, para $35 \%$. É importante notar que ainda existem grandes diferenças entre as regióes Sul, Sudeste e Centro-Oeste e as do Norte e Nordeste no que diz respeito à formação de professores. Enquanto dois terços dos professores no primeiro grupo têm curso superior, apenas um terço deles no segundo grupo têm a mesma qualificação. 
Tabela 1 - Professores com ensino médio incompleto

e curso superior no Brasil (1996 e 2006)

\begin{tabular}{|c|c|c|c|c|}
\hline & \multicolumn{2}{|c|}{$\begin{array}{c}\text { Ensino médio incompleto } \\
\%\end{array}$} & \multicolumn{2}{|c|}{$\begin{array}{c}\text { Curso superior } \\
\%\end{array}$} \\
\hline & 1996 & 2006 & 1996 & 2006 \\
\hline Brasil & 15,3 & 1,0 & 20,3 & 57,7 \\
\hline Norte & 33,3 & 2,2 & 2,7 & 34,9 \\
\hline Nordeste & 27,7 & 1,7 & 7,8 & 35,2 \\
\hline Sudeste & 2,9 & 0,3 & 31,3 & 74,2 \\
\hline Sul & 5,6 & 0,5 & 32,1 & 71,9 \\
\hline Centro-Oeste & 11,4 & 1,1 & 26,2 & 73,7 \\
\hline
\end{tabular}

Fonte: Censo Escolar, Inep/MEC.

Apesar do aumento da escolaridade dos professores do ensino fundamental, o desempenho dos alunos de ensino básico não aumentou no mesmo período no país. Se partimos do pressuposto de que a qualidade dos professores é de fato um dos melhores preditores para a aprendizagem dos alunos, temos que ir além do nível de escolaridade desses docentes e da qualidade dos cursos de formaçáo de professores, assim como a atratividade da carreira do magistério no Brasil.

\section{Quão atraente é a carreira docente?}

A literatura internacional sobre incentivos sugere que a atratividade da carreira docente pode estar ligada a diversos fatores, entre eles 4 :

1. Flexibilidade. A maioria dos professores tem a opçáo de trabalhar em tempo parcial e acomodar outros trabalhos dentro ou fora da escola onde atuam, de acordo com suas necessidades pessoais e financeiras;

2. Férias. Os professores têm geralmente férias mais longas (e mais frequentes) do que profissionais de outras áreas;

3. Taxas de desemprego baixas. Os professores raramente ficam desempregados por longos períodos de tempo;

4. Altruismo. Os professores acreditam que podem contribuir para o desenvolvimento social.

Atualmente não existem estudos quantitativos que documentem a atratividade da carreira docente no Brasil. Entretanto, a pesquisa qualitativa sugere que o benefício mais significativo oferecido - estabilidade no emprego para os contratados -

${ }^{4}$ World Bank (2005) e OECD (2005). 
não é suficiente para compensar as condiçóes negativas de trabalho, como o pouco reconhecimento público, e o baixo status, além dos baixos salários e poucas oportunidades de influenciar as políticas públicas, especialmente aquelas que afetam o trabalho docente em sala de aula (Moreira, 1999; Lapo; Bueno, 2002).

Dada a falta de dados sobre a maioria destes benefícios, nossa análise incidirá somente sobre os salários dos professores. A evidência empírica mostra que existe relação entre incentivos financeiros e a entrada na carreira docente ${ }^{5}$. De acordo com a Pesquisa Nacional por Amostra de Domicílio (PNAD) as ocupaçóes no setor privado compreendem o maior grupo de trabalho no Brasil (75\%), seguido por outras ocupaçóes no setor público (20\%). Professores das escolas públicas e particulares representam apenas $4,4 \%$ e $1,1 \%$ da população ativa, respectivamente.

A tabela 2 mostra as diferenças salariais entre esses grupos profissionais ${ }^{6}$. Trabalhadores com níveis mais elevados de escolaridade, que idealmente deveriam ser atraídos para a carreira docente, encontram oportunidades de emprego com muito melhor remuneraçáo no setor privado. Em média, um professor na escola pública ganha $36 \%$ menos do que outros trabalhadores qualificados no setor privado e $19 \%$ menos do que seus colegas em escolas particulares. As diferenças são ainda mais acentuadas entre os professores de escolas públicas e outras ocupações no setor público ( $52 \%$ menos).

Tabela 2 - Diferenças salariais entre professores de escolas públicas e grupos de comparação (médias para 1995 a 2006)

\begin{tabular}{lccc}
\hline $\begin{array}{c}\text { Escolaridade do } \\
\text { trabalhador }\end{array}$ & $\begin{array}{c}\text { Outras ocupaçöes } \\
\text { no setor privado } \\
\%\end{array}$ & $\begin{array}{c}\text { Outras ocupações } \\
\text { no setor público } \\
\%\end{array}$ & $\begin{array}{c}\text { Professores do } \\
\text { setor privado } \\
\%\end{array}$ \\
\hline Educação superior & $-36,0$ & $-52,1$ & $-19,3$ \\
Educação secundária & 33,5 & 0,9 & $-1,5$ \\
\hline
\end{tabular}

Fonte: PNAD/IBGE, 1995 a 2006 in Moriconi (2008).

\footnotetext{
${ }^{5}$ Vide Barros, Mendonça e Blanco (2001), Afonso, Barbosa Filho, Pessôa (2007) e Moriconi (2008) para estudos sobre a remuneraçáo de professores no Brasil. Para estudos internacionais, vide Allegretto, Corcoran, Mishel (2004), Hernani-Limarino (2005) e Asadullah (2006).

6 Moriconi (2008) utilizou a técnica de Oaxaca para controlar as características dos trabalhadores e estimar a diferença entre os salários dos professores do setor público e outros grupos de comparaçáo (outras profissōes nos setores público e privado, e professores das escolas particulares) com mesmo nível de escolaridade.
} 
No entanto, no mesmo período (1995 a 2006), o salário dos professores de escolas públicas aumentou sensivelmente em relação a outras ocupaçóes. Esses professores ganhavam $62 \%$ menos que outras profissóes do setor privado em 1995, e em 2006 a diferença caiu para $17 \%$.

Tabela 3 - Diferenças salariais entre professores de escolas públicas e grupos de comparação (para trabalhadores com educação superior)

\begin{tabular}{cccc}
\hline Ano & $\begin{array}{c}\text { Outras ocupações } \\
\text { no setor privado } \\
\%\end{array}$ & $\begin{array}{c}\text { Outras ocupaçōes } \\
\text { no setor público } \\
\%\end{array}$ & $\begin{array}{c}\text { Professores do } \\
\text { setor privado } \\
\%\end{array}$ \\
\hline 1995 & $-61,9$ & $-60,4$ & $-30,1$ \\
2006 & $-16,8$ & $-43,3$ & $-4,7$ \\
\hline
\end{tabular}

Fonte: PNAD/IBGE, 1995 e 2006 in Moriconi (2008).

Enquanto esta análise leva em conta a compensação financeira média dos professores públicos em relação às ocupaçōes em outros setores, a comparação entre os salários iniciais ajuda a explicar a capacidade de atraçâo dos melhores candidatos para a carreira docente. A tabela 4 mostra as diferenças salariais estimadas por anos de experiência. Professores com até dois anos de experiência no mercado de trabalho ganhavam menos do que seus pares em outras profissóes nos setores privado e público ( $4,4 \%$ e $32,6 \%$, respectivamente). A diferença salarial aumenta significativamente entre indivíduos com 20 ou mais anos de experiência. Esses resultados sugerem que, além de salários iniciais pouco competitivos, a carreira docente náo parece promissora no longo prazo, pois para indivíduos com mais experiência de trabalho, outras ocupaçóes que não o ensino são mais vantajosas financeiramente.

Tabela 4 - Diferenças salariais entre professores de escolas públicas e grupos de comparação de acordo com anos de experiência (para trabalhadores com educação superior)

\begin{tabular}{lccc}
\hline $\begin{array}{c}\text { Anos de } \\
\text { experiência }\end{array}$ & $\begin{array}{c}\text { Outras ocupaçōes no } \\
\text { setor privado } \\
\%\end{array}$ & $\begin{array}{c}\text { Outras ocupações } \\
\text { no setor público } \\
\%\end{array}$ & $\begin{array}{c}\text { Professores do } \\
\text { setor privado } \\
\%\end{array}$ \\
\hline Até 2 anos & $-4,4$ & $-32,6$ & 3,6 \\
20 anos ou mais & $-34,9$ & $-46,2$ & $-6,4$ \\
\hline
\end{tabular}

Fonte: PNAD//BGE, 2006 in Moriconi (2008). 


\section{Quem está sendo atraído para a carreira docente?}

Atualmente, náo há estudos empíricos que analisam a qualificação dos candidatos à carreira docente no Brasil. No entanto, os dados do Exame Nacional do Ensino Médio (Enem) nos permite analisar aqueles que pretendem cursar algum curso superior que prepare para o magistério. O Enem é um exame feito por estudantes que terminam (ou estão prestes a concluir) o ensino médio e que pretendem ingressar numa universidade. Além de ser testado no conhecimento das disciplinas básicas, os alunos que participaram do Enem em 2005 responderam a perguntas sobre suas condições socioeconômicas, seu background familiar, e seus futuros planos de carreira.

Os resultados, apresentados na figura 3, mostram que $11 \%$ de todos os alunos que fizeram o exame estavam interessados em se tornar professores do ensino fundamental ou médio. Entre esses, apenas $5 \%$ estavam entre os $20 \%$ dos estudantes com melhor desempenho, e $16 \%$ estavam entre os $20 \%$ com pior desempenho. Isso significa que apenas $10 \%$ dos interessados na carreira docente estáo entre os melhores alunos do ensino médio do país. Por outro lado, cerca de um terço dos estudantes interessados na carreira docente estão entre os piores em sua coorte. Vale ressaltar que na Finlândia os professores estâo entre os 10\% melhores alunos da coorte. Estes dados sugerem que a carreira docente no Brasil parece atrair uma porcentagem elevada de estudantes menos qualificados.

À semelhança do Enem, o Exame Nacional de Desempenho dos Estudantes (Enade) fornece informaçóes sobre as características de formação do estudante e nos permite comparar candidatos que optaram por campos distintos de estudo. Todos os estudantes que entram numa instituição de ensino superior e concluem a graduação submetem-se a esse exame. Nossa análise compara estudantes de Pedagogia com estudantes de Engenharia. Além de ambas as carreiras terem participado do Enade 2005, Engenharia e Pedagogia são duas áreas de estudo que gozam de status bastante diferente na sociedade brasileira e tradicionalmente atraem indivíduos de grupos socioeconômicos muito distintos. 
Figura 3 - Desempenho no Enem e opção profissional

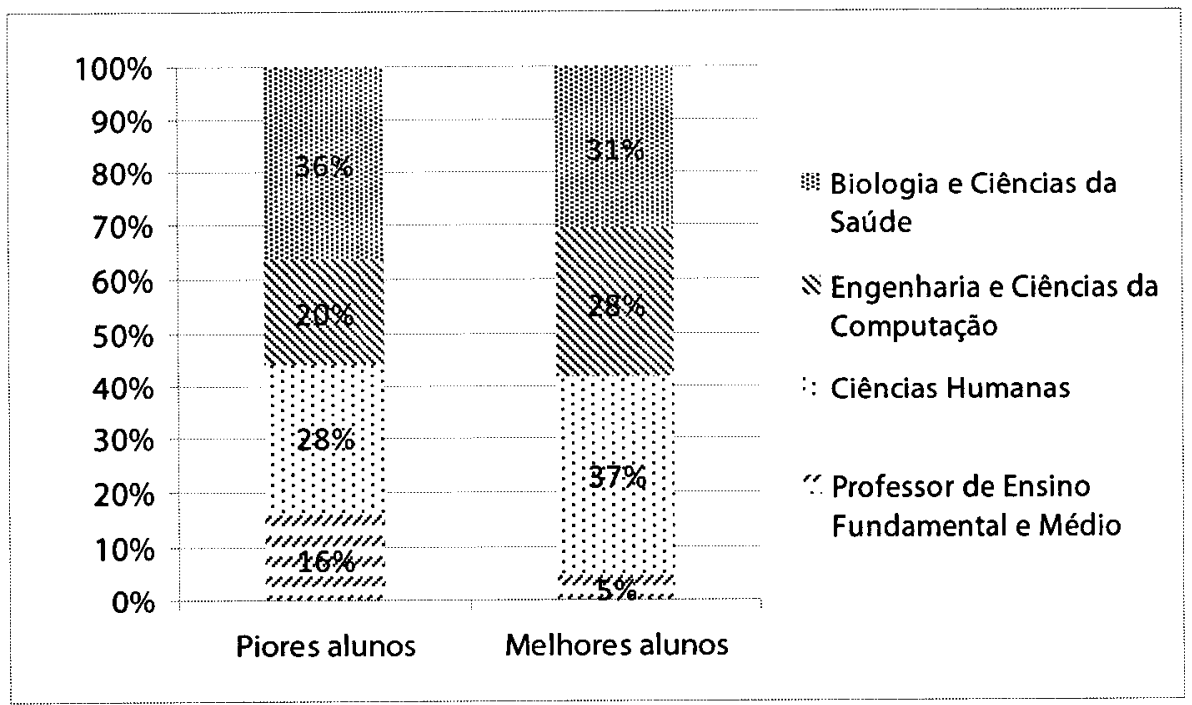

Fonte: Enem/Inep, 2005.

Como a tabela 5 indica, há uma porcentagem muito maior de estudantes de Pedagogia que frequentaram escolas públicas do que estudantes de Engenharia. Como, na média, o desempenho dos alunos das escolas públicas é inferior ao das escolas privadas, podemos inferir que no geral os estudantes de Pedagogia entram na universidade menos preparados do que seus colegas de Engenharia. Da mesma forma, os níveis de escolaridade materna e a renda familiar sáo muito mais baixos entre os estudantes de Pedagogia que de Engenharia. Como vários estudos apontam, a escolaridade materna e a renda têm forte correlaçáo com o desempenho do estudante. Outra evidência dos diferentes perfis socioeconômicos de estudantes de Engenharia e Pedagogia reside na porcentagem de alunos que trabalhavam ao mesmo tempo em que estudavam. Em média, há maior porcentagem de estudantes de Engenharia cujas famílias ganhavam mais de três salários mínimos e que não tinham de trabalhar enquanto estavam na universidade. Este fator está associado com a alocação de tempo aos estudos por parte dos alunos antes da formatura. Os alunos cujas famílias são pobres e que precisam trabalhar enquanto estudam são menos propensos a dedicar tempo aos estudos e, portanto, têm menor possibilidade de obter sucesso acadêmico. 
Tabela 5 - Características dos estudantes que ingressam em Pedagogia e Engenharia

\begin{tabular}{|c|c|c|}
\hline & $\begin{array}{c}\text { Pedagogia } \\
\% \\
\end{array}$ & $\begin{array}{c}\text { Engenharia } \\
\% \\
\end{array}$ \\
\hline \multicolumn{3}{|l|}{ Onde você cursou o ensino médio? } \\
\hline Escola pública & 80 & 45 \\
\hline Escola particular & 20 & 55 \\
\hline \multicolumn{3}{|l|}{ Escolaridade materna } \\
\hline $4^{\text {a }}$ série ou menos & 50 & 19 \\
\hline $5^{\mathrm{a}}$ a $8^{\mathrm{a}}$ séries & 19 & 16 \\
\hline Ensino médio & 22 & 35 \\
\hline Faculdade & 9 & 30 \\
\hline \multicolumn{3}{|l|}{ Renda familiar } \\
\hline Menos de 3 SM & 48,5 & 12 \\
\hline 3 a $10 \mathrm{SM}$ & 15 & 56 \\
\hline 11 a 20 SM & 5 & 21 \\
\hline Mais de 20 SM & 1,5 & 11 \\
\hline \multicolumn{3}{|l|}{ Status de trabalho do estudante } \\
\hline Não trabalha & 27 & 47 \\
\hline Trabalha, mas não dá dinheiro à família & 36 & 33 \\
\hline Trabalha e dá algum dinheiro à família & 37 & 20 \\
\hline
\end{tabular}

Fonte: Enade/Inep, 2005.

Embora náo se possa fazer inferências sobre o real desempenho dos alunos de Pedagogia em instituiçóes de ensino superior com base nas informaçōes apresentadas na tabela 5 , os dados lançam luz sobre o perfil dos indivíduos atraídos para a carreira docente no Brasil e a associação entre essas características e o desempenho acadêmico.

\section{FORMAÇÃO DE PROFESSORES \\ Quem forma os professores no Brasil?}

Segundo a OCDE (2005), a carreira de professor deve ser pensada como um processo de aprendizagem constante, e náo somente como a oferta de uma formação inicial. De fato, os países de melhor desempenho no PISA empenham-se em náo só oferecer formaçáo de qualidade aos professores iniciantes, mas também oportunidades e incentivos para o desenvolvimento profissional contínuo ao longo da sua carreira. No entanto, a formação inicial de professores não deixa de ser um alicerce importante para a atuação desse profissional. 
Ao contrário desses melhores sistemas - onde a seleção para ser professor ocorre antes do ingresso em curso de formaçáo docente - no Brasil futuros professores buscam uma colocação no mercado de trabalho depois de passarem por programas de formação universitária. Para se tornar professor em escolas públicas brasileiras, os formados prestam concurso público composto por prova escrita e análise das credenciais profissionais (experiência anterior como professor e formação complementar). Năo há avaliaçóes práticas. Embora, em teoria, haja um período probatório durante o qual os professores recém-selecionados podem ser avaliados antes de se tornarem efetivos, essa prática raramente vigora. Além disso, cada Estado e município tem seu próprio sistema de ensino, de modo que os processos de seleçáo pública não são unificados.

Os países de alto desempenho, como Finlândia e Cingapura, selecionam seus professores antes de lhes oferecer a formação específica para a docência; isso significa que esses países concentram seus esforços e recursos em formar apenas aqueles que vão ocupar postos de trabalho. Além disso, por estarem diretamente vinculados ao mercado de trabalho, a interação dos futuros professores com a escola é intenso. Preparação de aulas, aulas práticas, estratégias para ensinar alunos com dificuldades de aprendizagem são parte importante do curso de formação docente.

Atualmente, existem no Brasil 2.500 programas de formaçáo voltados para professores de educação infantil e primeiro ciclo do ensino fundamental (Normal Superior e Pedagogia) e mais de 4.000 programas para formaçáo de professores do segundo ciclo do ensino fundamental e ensino médio (Licenciaturas). Como mostra a tabela 6 , os programas de formaçáo de professores representam $30 \%$ de todos os programas de ensino superior no País. Portanto, a matrícula em programas de formação de professores é alta em comparação com as demais carreiras.

Tabela 6 - Número de programas de formação de professores no Brasil

\begin{tabular}{lrc}
\hline Tipos de curso de graduação & $\mathbf{N}$ & $\%$ \\
\hline Pedagogia & 1.584 & 24 \\
Normal superior & 855 & 13 \\
Licenciaturas & 4.109 & 63 \\
Total de cursos de formação de professores & 6.548 & 30 \\
Total de cursos de graduação & 22.101 & \\
\hline
\end{tabular}

Fonte: Censo do Ensino Superior/Inep، 2006.

Atualmente, existem 900.000 pessoas recebendo formaçáo para serem professores -360.000 delas especializando-se no primeiro ciclo do ensino fundamental. No entanto, nem todos vão se tornar professores. Na verdade, segundo o 
Ministério da Educação há escassez de professores qualificados em algumas regióes do País e para algumas disciplinas (Ristoff, 2008).

Até 1996, os professores do primeiro ciclo do ensino fundamental necessitavam apenas de um diploma de ensino médio profissionalizante para ensinar (Magistério). No entanto, após a aprovação da nova lei (LDB n. 9394/96) determinou-se que, até 2007, todos os professores da educação básica deveriam ser formados em instituiçôes de ensino superior. Como resultado, houve um boom no número de programas concebidos para treinar professores do ensino fundamental, principalmente no setor privado (ver Figura 4). Outro aspecto da nova legislação foi a criação do curso Normal Superior, uma versão mais curta dos programas de Pedagogia. Em geral, esses programas têm duraçáo média de três anos, enquanto os de Pedagogia duram quatro anos. Embora ambos sejam considerados programas de educação superior, o Normal Superior acabou se tornando um programa para formar profissionais em exercício que não tinham as qualificaçóes adequadas no âmbito da nova lei.

Figura 4 - Mudança no número de cursos de formação de professores de ensino fundamental no Brasil (2001-2006)

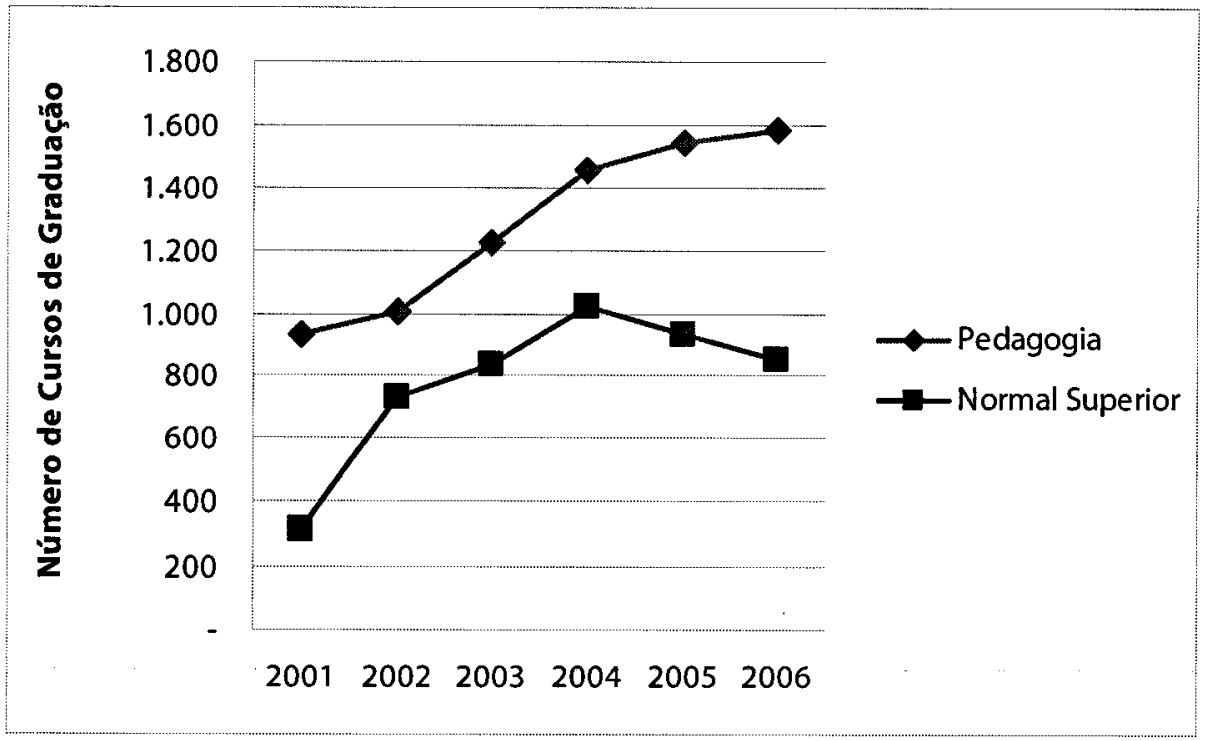

Fonte: Censo do Ensino Superior/lnep, 2001-2006.

Antes de 1996, os cursos de Pedagogia preparavam tanto professores para a docência nos cursos profissionalizantes de Magistério quanto para o primeiro ciclo do ensino fundamental. Os cursos de Pedagogia também preparavam diretores de 
escolas, supervisores e coordenadores pedagógicos, sendo que cada uma dessas áreas tinha um currículo nacional comum. As discussóes sobre como reorganizar a formação desses professores começou em 1997, porém, somente em 2005, foi estabelecida uma nova norma nacional. Em primeiro lugar, o currículo nacional comum foi substituído por diretrizes nacionais. De acordo com essas orientaçóes, a Pedagogia deveria focar na preparaçáo de professores, tanto para a educação infantil quanto para o primeiro ciclo do ensino fundamental. As novas diretrizes determinam que a formação deve variar entre 2.800 a 3.600 horas ( 3 a 4 anos letivos) divididos em:

- Créditos: com foco em teorias relacionadas ao ensino e aprendizagem, prática pedagógica, orientaçáo de alunos, planejamento e avaliação educacional, e políticas públicas na educação (2.500/3.000 horas).

- Estágio ou prática: relacionado à observação, bem como à participação no planejamento, na execução e avaliaçáo das atividades educativas (300/600 horas).

- Pesquisa ou atividades práticas: (Iniciação Científica e Extensão) relacionadas a outras atividades curriculares orientadas por professores da Faculdade de Educação (não obrigatórias).

A definiçáo sobre o foco do curso, mais especificamente a divisão dos créditos, fica a critério de cada universidade ou faculdade, e no geral há pouca homogeneidade nos currículos dos cursos de Pedagogia no País. O debate educacional se concentra em torno da ênfase que deve ser dada às disciplinas de conhecimentos gerais - tais como Filosofia, Sociologia e Psicologia - e às metodologias de ensino (metodologia do ensino de ciências, por exemplo) ou mesmos disciplinas voltadas à gestão da sala de aula. Apesar do tema gerar grande controvérsia, não há pesquisas empíricas que avaliem a formação inicial de professores no Brasil e a eficácia de diferentes currículos na capacitação do docente para o ensino.

\section{Qual a qualidade dos programas de formaçáo de professores?}

Avaliar a qualidade dos programas de formação de professores, principalmente no que diz respeito ao possível impacto que o futuro professor formado em determinado programa terá junto aos seus alunos, não é tarefa fácil. Nos Estados Unidos, Rice (2003) concluiu que disciplinas que focam em conteúdos destinados a desenvolver habilidades essenciais nos professores, tais como metodologias de ensino, gestão da sala de aula, avaliação escolar e desenvolvimento curricular, contribuem para 
a eficácia do trabalho docente somente quando combinadas com o conhecimento sólido do conteúdo a ser ensinado. Portanto, foco em disciplinas mais práticas associadas ao domínio do conteúdo parece ser o mais importante.

No Brasil, o debate sobre a qualidade dos professores sempre esteve relacionado a maiores níveis de escolaridade, portanto a falta de diploma de nível superior por uma parcela considerável dos professores explicava a baixa qualidade do ensino. Entretanto, a pesquisa internacional que examina a associação entre a formação de professores e o desempenho dos alunos apresenta resultados controversos. Utilizando os dados do Terceiro Estudo Internacional de Matemática e Ciências sobre o desempenho de alunos com 13 anos de idade em 39 países, Wößmann (2003) constatou que o nível de escolaridade dos professores tem relaçáo positiva com o desempenho do aluno. No entanto, segundo Rice (2003), as evidências americanas sobre o nível de escolaridade dos professores no desempenho dos alunos não são tão conclusivas.

No Brasil, a pesquisa quantitativa mostra que a formação em nível superior tem pouco ou nenhuma correlaçáo com o desempenho dos alunos, principalmente nas séries iniciais (Menezes-Filho, 2007; Soares, 2003; Louzano, 2007). Uma possível explicação para esses resultados é a má qualidade dos cursos de formação de professores vigentes no País. Nos últimos dez anos o boom mal regulamentado das instituiçóes de Pedagogia e Normal Superior pode ser parte dessa explicaçáo.

Com o objetivo de medir a qualidade dos cursos de nível superior no Brasil, entre eles os de Pedagogia, o Ministério da Educação vem desenvolvendo indicadores. Desde 1996, o Brasil usa o exame Enade como uma aproximação da qualidade dos graduados em programas de ensino superior ${ }^{7}$. Este exame é específico para cada carreira, e baseia-se numa amostra de graduados e numa amostra de alunos recém-admitidos. Como medida de qualidade institucional, foram desenvolvidos dois índices: o Conceito Enade e o Conceito IDD. O primeiro representa a pontuação média do programa, e o último o valor que o curso agrega ao aluno. Ambos os índices variam de 1 a 5 .

Há muita controvérsia em torno da precisão técnica e posterior utilização desses índices (Schwartzman, 2005). O Conceito IDD foi desenvolvido como forma de compensar as diferenças de formação no nível dos ingressantes entre as diversas instituiçóes. Em média, as instituições públicas tendem a receber estudantes mais preparados do que as particulares. Portanto, muito poucas instituiçóes particulares iriam

${ }^{7}$ No período, houve mudanças no nome e no desenho dessas avaliaçôes. 
conseguir as pontuaçóes mais altas no Conceito Enade ( 4 e 5). Como o Conceito IDD tenta medir o valor agregado pelas instituições, esse problema seria minimizado.

No entanto, esses índices não são uma medida objetiva de qualidade. Representam a posiçáo de determinada instituiçâo ou programa em relação às outras instituiçóes dentro da mesma carreira, e náo o nível de qualidade ideal esperado de um programa. Se dentro de uma carreira as médias forem baixas, como é o caso da Pedagogia, estar acima da média não significa ter boa qualidade (só significa que o programa é melhor do que a média de programas do mesmo tipo). Medir de fato a qualidade de um programa de formaçáo de professores, implicaria definir de antemâo um conjunto de habilidades e competências que esses cursos deveriam desenvolver nos futuros professores, o que não ocorre no caso do Enade e seus indicadores.

Atualmente, o Brasil náo dispóe de instrumentos para avaliar a qualidade "ideal” dos seus programas de formação de professores. Embora limitados, os indicadores disponíveis - principalmente os resultados do Enade - mostram que os estudantes de Pedagogia têm a menor média em comparação com outros programas de formação de professores (Licenciaturas) que recebem alunos com características de formaçáo semelhantes (Brito, 2007). Assim, os programas de Pedagogia precisam ser mais estudados.

\section{Estudo empírico sobre a formação inicial de professores}

Em 2005, mais de 55.000 estudantes de mais de 600 cursos de Pedagogia diferentes participaram do Enade. A tabela 7 mostra a distribuição dos resultados do Conceito Enade e do Conceito IDD entre os programas. Enquanto $27 \%$ dos programas têm a maior pontuação no Conceito Enade, 30\% têm o Conceito IDD mais baixo. Como a pontuação é convertida para uma distribuição normal, as tabelas a seguir não mostram que $27 \%$ dos programas que recebem notas de 4 e 5 no Enade são programas bons e que os abaixo da média ( 1 e 2) são ruins. Elas mostram a distribuição dos programas acima e abaixo da média. 
Tabela 7 - Conceito Enade ( $n=646)$ e Conceito IDD ( $n=599)$ para programas de Pedagogia

\begin{tabular}{ccccc}
\hline \multirow{2}{*}{ Conceito } & \multicolumn{2}{c}{ Conceito Enade } & \multicolumn{2}{c}{ Conceito IDD } \\
\cline { 2 - 5 } & Programas & $\%$ & Programas & $\%$ \\
\hline 1 & 13 & 2 & 22 & 4 \\
2 & 87 & 13 & 150 & 25 \\
3 & 374 & 58 & 251 & 41 \\
4 & 160 & 25 & 136 & 23 \\
5 & 12 & 2 & 40 & 7 \\
\hline
\end{tabular}

Fonte: Enade/Inep, 2005.

Do ponto de vista da política pública, este indicador nos ajuda apenas a identificar a posição de um programa em relação a outros, dentro de um Estado ou mesmo do País. No entanto, não nos diz nada sobre a qualidade dos programas de Pedagogia, quanto eles preparam os futuros professores para a sala de aula e o possível impacto na aprendizagem dos alunos das escolas brasileiras.

Na tentativa de remediar o problema, em 2008, o Ministério da Educação criou um novo índice que integra outras dimensóes ao exame do aluno. O Conceito Preliminar de Curso (CPC) combina os dois índices anteriormente descritos (Conceito IDD e Conceito Enade), com medidas da qualidade dos professores (avaliada por meio de suas credenciais acadêmicas e do tempo dedicado ao programa), e a disponibilidade de recursos institucionais. Este indicador pressupóe que, em média, os recursos e as qualificaçóes dos professores tornam um programa melhor. No entanto, restam algumas questóes. Isso é verdade para a formação inicial de professores? O que faz um bom programa de ensino? Usando os dados do Enade 2005 para os programas de Pedagogia, este estudo empírico explora a relação entre fatores institucionais e os resultados dos graduados no exame.

Uma forma possível de criar indicadores para avaliar a qualidade de um programa reside em identificar as características institucionais associadas a níveis mais elevados de desempenho dos alunos ao final do programa. Neste estudo analisamos uma amostra de 20.480 graduados em Pedagogia de 532 instituiçóes dos 27 estados brasileiros. Além do resultado das provas, o conjunto de dados contém informações sobre formaçáo dos estudantes e suas percepçôes sobre o programa.

A pontuaçáo média da Pedagogia no Enade 2005 é de 49, e como se trata de uma prova clássica, isso significa que, em média, os graduados em Pedagogia acer- 
tam $49 \%$ do exame (Tabela 8 ). Como não existe um resultado esperado para esta prova, este dado pode ser interpretado apenas de maneira comparativa.

Tabela 8 - Características dos graduados em Pedagogia $(n=20,480)$

\begin{tabular}{ll}
\hline Características dos alunos & \\
\hline Resultado médio do Enade & 49 \\
Feminimo & $92 \%$ \\
Idade média & 32 \\
Negro ou pardo & $36 \%$ \\
Renda familiar mensal & \\
$\quad$ menos de 3 SM & $37 \%$ \\
3 a 10 SM & $53 \%$ \\
11 a 20 SM & $7 \%$ \\
$\quad$ acima de 20 SM & $3 \%$ \\
Experiência docente anterior & $72 \%$ \\
\hline
\end{tabular}

Fonte: Enade/Inep, 2005.

Noventa e dois por cento dos graduados em Pedagogia são do sexo feminino, e tem em média 32 anos. Ao redor de $36 \%$ dos graduados são pardos ou negros. Quase $40 \%$ dos graduados têm renda familiar inferior a 3 salários mínimos. É importante notar que $72 \%$ deles têm experiência docente anterior.

A pesquisa educacional tem demonstrado de forma consistente que a maior parte da variaçáo no desempenho e na aprendizagem dos alunos deve-se às diferenças em seu background, isto é, suas habilidades anteriores e as características de sua família e comunidade. Portanto, um modelo que pretenda analisar a influência de um programa no desempenho de um graduado deve ser capaz de controlar esses fatores.

A tabela 9 mostra que $86 \%$ dos programas de Pedagogia são particulares. A maioria está concentrada nas regióes Sudeste (54\%) e Sul (17\%). Menos de um terço dos programas de formação inicial (29\%) estão nas regiōes Norte, CentroOeste e Nordeste. 
Tabela 9 - Características institucionais $(n=532)$

\begin{tabular}{ccc}
\hline & Porcentagem & Resultado médio \\
\hline Pública & 14 & 50 \\
Particular & 86 & 48 \\
CO & 12 & 45 \\
NO & 5 & 46 \\
NE & 12 & 47 \\
SE & 54 & 50 \\
S & 17 & 50 \\
\hline
\end{tabular}

Fonte: Enade/Inep، 2005.

A fim de analisar a relação entre o desempenho dos graduados e os fatores institucionais, desenvolvemos dois índices que tentam captar o nível dos recursos institucionais e as competências adquiridas pelos alunos no curso. O Índice de Competências é composto por 12 itens e representa a percepção dos graduados em relação à capacidade que o curso teve em desenvolver habilidades essenciais nos futuros profissionais. Por outro lado, o Índice de Recursos é formado por dez itens e representa a percepção dos alunos sobre os recursos disponíveis em nível institucional (ver Apêndice 1 para detalhes sobre os itens utilizados no desenvolvimento desses índices).

Tabela 10 - Estatísticas descritivas para o índice de recursos do programa e o índice de competências

\begin{tabular}{lcccc}
\hline \multicolumn{1}{c}{ Variáveis (range) } & Mínimo & Máximo & Média & $\begin{array}{c}\text { Desvio } \\
\text { Padrão }\end{array}$ \\
\hline Indice de recursos (0-40) & 9,8 & 39,0 & 28,9 & 3,8 \\
Indice de competências (0-52) & 27,2 & 52,0 & 41,5 & 3,3 \\
\hline
\end{tabular}

Fonte: Enade/Inep, 2005.

A tabela 10 apresenta as características descritivas desses dois índices. Quanto maior o índice de competência de um programa mais seus alunos acreditam que o curso foi capaz de prepará-los para a vida profissional. Da mesma maneira, quanto maior o índice de recursos de um programa maior é a percepçáo dos alunos de que o curso dispunha dos recursos necessários para o ensino efetivo. Como indica a tabela 10, há mais variação no índice de recursos do que no índice de competências. Além disso, a média para o primeiro é menor do que para o último. Isso mostra que, no 
caso do índice de competências, a maioria dos programas é bem avaliada por seus graduados, ou seja, em uma escala de $0-52$, a média obtida foi 41 . Revela também que há muito menos homogeneidade nos recursos disponíveis aos alunos nos diferentes cursos de Pedagogia do País.

Com o objetivo de testar a hipótese de que diferenças institucionais dos cursos de Pedagogia (gestão pública ou privada, recursos disponíveis, capacidade de desenvolver determinadas habilidades nos alunos) estão associadas às diferenças na qualidade desses programas, medida pela nota Enade dos seus graduados, foi desenvolvido um modelo multinível que correlaciona os resultados dos graduados no exame com as suas características e a dos programas.

O modelo final de análise (ver Apêndice 2) produziu os resultados apresentados a seguir:

\section{Características dos alunos e pontuação Enade}

Conforme esperado, sexo, raça e renda têm associaçáo negativa com a pontuação Enade. Além disso, o fato de o estudante de Pedagogia ter experiência docente anterior à sua graduaçáo mostra uma associaçáo positiva com a nota Enade do graduado, mantendo todas as demais variáveis constantes.

\section{Características dos cursos de Pedagogia e pontuação Enade}

O nível de recursos disponíveis para os alunos nos cursos de Pedagogia tem uma relação positiva com o resultado do Enade. No entanto, o desenvolvimento de competências não foi estatisticamente significativo. Além disso, a regiáo onde está localizado o programa também parece importar. Em média, os alunos matriculados em programas localizados nas regiōes Sul e Sudeste têm pontuação superior aos estudantes matriculados em instituiçóes localizadas nas regióes Norte, Nordeste e Centro-Oeste' ${ }^{9}$, controlando as demais variáveis.

${ }^{8}$ Como a pergunta que orienta este estudo e os dados utilizados são multiníveis, foram utilizadas técnicas de modelagem multinível. Esse método é recomendado quando duas fontes de dados provenientes de dois ou mais níveis de hierarquia sáo combinados (Lee; Bryk, 1989; Raudenbush; Bryk, 2002). Neste estudo, os graduados estão inseridos dentro de programas. Assim, os dados dos graduados representam o nível mais baixo, e os dados do programa o nível mais elevado. ${ }^{9} \mathrm{O}$ teste de hipótese linear geral não indicou diferenças entre as regióes Sul e Sudeste, bem como entre o Norte, Nordeste e Centro-Oeste. Portanto, essa variável indica se o programa pertence a um desses dois grupos. 
Além disso, alunos graduados de cursos de Pedagogia de instituições públicas têm desempenho superior, no Enade, aos de cursos privados, controlando as características dos estudantes. No entanto, a relação entre a experiência anterior dos graduados com a docência e a nota Enade pode variar entre os diferentes cursos de Pedagogia. Observamos que entre os graduados com experiência prévia em sala de aula ( $72 \%$ do total da amostra) não se observa diferença entre as instituiçóes públicas e privadas.

Ainda que cursos de Pedagogia de instituições públicas sejam em média melhores que os privados, mesmo levando em consideração as diferenças de nível socioeconômico de seus egressos, essa vantagem desaparece quando se leva em conta a experiência docente prévia dos graduados. Se considerarmos que esse é o caso de mais de dois terços dos indivíduos que egressam de programas de Pedagogia do país, podemos dizer que na maioria dos casos náo se observa diferença no resultado Enade dos graduados oriundos de cursos de Pedagogia de instituiçóes públicas ou privadas.

\section{CONCLUSÃO}

Os problemas que o Brasil encontra para selecionar e contratar bons professores para a rede pública de ensino são muitos. Neste trabalho buscou-se identificar alguns dos fatores associados a essas dificuldades. Há poucos incentivos financeiros para os melhores alunos do ensino médio se tornarem professores. Embora as disparidades salariais entre os professores do setor público e as demais carreiras tenham diminuído ao longo dos anos, os professores com nível superior recebem, em média, salários mais baixos do que outros profissionais, tanto do setor público como do privado. Além disso, essa diferença aumenta significativamente com os anos de experiência. De qualquer forma, o salário inicial de um professor do setor público ainda é mais baixo que o de outras carreiras. A essa baixa remuneração soma-se o baixo status social da carreira.

Diferentemente dos países de alto desempenho, o Brasil atrai indivíduos com baixo rendimento acadêmico e com perfil socioeconômico mais baixo para programas de formaçáo de professores. Além do perfil dos que são atraídos para a carreira docente, há que se levar em conta também a qualidade da formação oferecida a esses futuros professores.

É importante notar que a expressiva mudança no perfil educacional dos professores brasileiros nos últimos anos não produziu melhorias no desempenho dos alunos nos testes padronizados nacionais. Apesar do esforço de levar educaçáo superior aos professores, cursos de baixa qualidade podem tê-lo comprometido. Nosso 
estudo empírico buscou analisar a qualidade desses cursos utilizando os dados do Enade. Ele revelou que os cursos de Pedagogia das instituiçóes públicas são, na média, melhores que os das instituiçóes privadas, mesmo quando levamos em consideração o contexto socioeconômico dos alunos desses cursos. No entanto, essa vantagem desaparece quando se considera a experiência prévia na docência. Entre os graduados de Pedagogia que já deram aulas ou já são professores - dois terços dos ingressantes dos cursos de Pedagogia - não se observam diferenças significativas no resultado Enade dos alunos de cursos públicos e privados.

Diferenças no currículo dessas instituiçóes talvez possam explicar essa relação aparentemente contraditória. Enquanto as instituiçóes públicas tendem a oferecer uma abordagem mais teórica, centrando-se na pesquisa educacional, instituiçóes particulares tendem a desenvolver uma abordagem mais pragmática do trabalho docente na formação de seus futuros professores. Assim, os indivíduos que já são professores, têm, provavelmente, expectativas diferentes, com relação a um programa de formação, daqueles que não têm experiência de sala de aula. Isso pode afetar sua relaçáo com o programa a ponto de, em um contexto mais teórico, como é o caso dos cursos de instituiçóes públicas de Pedagogia, esses alunos se sentirem mais desconectados, e isso afetar negativamente seu desempenho no Enade.

A falta de mais informaçōes acerca dos cursos de formação de professores, especialmente sobre seus currículos e abordagens, impede-nos de estimar a relação entre os resultados no Enade e as diferenças curriculares. Isso limita, portanto, a capacidade que esse tipo de estudo venha a ter no desenvolvimento e implementação de políticas públicas nessa área. $O$ desenvolvimento de padróes de desempenho docente, especificando o que se espera de um bom professor, poderia não só apoiar a avaliação dos cursos de Pedagogia, ao fornecer elementos mais precisos que os que hoje balizam o Enade, mas também servir de apoio para programas de seleçáo e certificaçáo docente.

Não há dúvidas de que para atrair indivíduos mais qualificados para a carreira docente devemos melhorar os incentivos salariais e o status social da profissão. No entanto, compreender a eficácia dos cursos de formação de professores, tanto das intituiçôes privadas como públicas, se faz urgente. Para isso, necessitamos de mais pesquisas que foquem nos desenhos curriculares e na capacidade que os distintos cursos têm de preparar os nossos futuros professores para o desafio das salas de aulas das escolas públicas brasileiras. 


\section{REFERÊNCIAS BIBLIOGRÁFICAS}

AFONSO, L.; BARBOSA FILHO, F.; PESSOAA, S. Um Estudo sobre os diferenciais de remuneração entre os professores das redes pública e privada de ensino. In: ENCONTRO DA ASSOCIAÇÃO NACIONAL DE PÓS-GRADUAÇÃO E PESQUISA EM ADMINISTRAÇÃO, 31., 2007, Rio de Janeiro. Anais... Rio de Janeiro: ANPAD, 2007.

ALLEGRETTO, S.; CORCORAN, S.; MISHEL, L. How does teacher pay compare? Methodological challenges and answers. Washington: Economic Policy Institute. 2004.

ASADULLAH, M. Pay differences between teachers and other occupations: some empirical evidence from Bangladesh. Journal of Asian Economics, n. 17, p. 1004-1065, 2006.

BARROS, R.; MENDONÇA, R.; BLANCO, F. O Mercado de trabalho para professores no Brasil. In: ENCONTRO NACIONAL DE ECONOMIA. Anais... - ANPEC, 29. Salvador, 2001.

BRITO, M. Enade 2005: perfil, desempenho e razão de opção dos estudantes pelas Licenciaturas. Avaliaçãa, Campinas, v. 12, n. 3, p. 401-443, 2007.

HERNANI-LIMARINO, W. Are teachers well paid in Latin America Countries? Relative wage and structures of returns of teachers. In: VEGAS, E. (Org.). Incentives to improve teaching: lessons from Latin America. Washington, D.C.: World Bank, 2005.

HAMMOND, L. Teacher quality and student achievement: a review of state policy evidence. Education Policy Analysis Archives, v. 8, n. 1, 2000.

LAPO, F. R.; BUENO, E. O. O Abandono do magistério: vínculos e rupturas com o trabalho docente. Psicol. USP, v. 13, n. 2, p. 243-276, 2002.

LEE, V.; BRYK, A. A Multilevel model of the social distribution of high school achievement. Sociology of Education, v. 62, $n$. 3, p. 172-192, 1989.

LOUZANO, P. Excellence and equity in Brazilian primary education. Thesis (Doctoral) - Harvard University, 2007.
MENEZES FILHO, N. Os Determinantes do desempenho escolar do Brasil. São Paulo: Instituto Futuro Brasil//BMEC, 2007.

MOREIRA, H. As Condições de trabalho do professor:uma realidade a ser enfrentada. Espaço Pedagógico, Piracicaba, v. 6, n. 2, p. 119-130, 1999.

MORICONI, G. Os Professores são mal remunerados nas escolas públicas brasileiras? Uma análise da atratividade da carreira do magistério sob o aspecto da remuneração. 2008. Dissertação (Mestrado) - Escola de Administração de Empresas de São Paulo, FGV, São Paulo, 2008.

ORGANIZATION FOR ECONOMIC COOPERATION AND DEVELOPMENT. Teachers matter: attracting, developing and retaining effective teachers. Paris: OECD, 2005.

RAUDENBUSH, S.; BRYK, A. Hierarchical linear models: applications and data analysis methods. 2nd. California: Sage, 2002.

RICE, J. Teacher quality: understanding the effectiveness of teacher attributes. Washington: Economic Policy Institute, 2003.

RISTOFF, Dilvo.ADemanda docentenaeducação básica e a nova Capes. 2008. Disponível em: <www.angrad.org.br/area_cientifical palestras/mapa_da_demanda_docente_na_ educacao_basica/655/download>.

RIVKIN, S. G.; HANUSHEK, E. A.; KAIN, J. F. Teachers, schools, and academic achievement. Econometrica, v. 73, n. 2, p. 417-458, Mar. 2005.

SANDERS, W.; RIVERS, J. Cumulative and residua effects of teachers on future student academic achievement: research progress report. University of Tennessee Value-Added Research and Assessment Center, 1996.

SCHWARTZMAN, S. O Enigma do Enade. 2005. Disponível em: <http://www.schwartzman. org.br/simon/enade.pdf>.

SOARES, J. F. Quality and equity in Brazilian basic education: facts and possibilities. In: SEMINAR ON EDUCATION IN BRAZIL. Paper... Oxford: 
Department of Educational Studies and Center Oxford Bulletin of Economics and Statistics, n. 65, for Brazilian Studies, Oxford University, 2003. v. 2, p. 117-170, 2003.

WÖBMANN, L. Schooling resources, WORLD BANK. Incentives to improve teaching: educational institutions and student lessons from Latin America. Washington: performance: the international evidence. World Bank, 2005.

Recebido em: maio 2010

Aprovado para publicação em: julho 2010 


\section{APÊNDICE 1}

A) Variáveis incluídas no Índice de Recursos (o número corresponde ao item do questionário da Enade 2005):

45. O espaço pedagógico é adequado ao número de estudantes?

46. O material de consumo oferecido é suficiente para o número de estudantes?

47. Os equipamentos disponiveis são suficientes para o número de estudantes?

50. Como você avalia o acervo da biblioteca, quanto à utilização, face às necessidades curriculares do seu curso?

51. Com relação aos livros mais usados no curso, o número de exemplares disponíveis na biblioteca atende ao alunado?

52. Como você avalia o acervo de periódicos científico-acadêmicos disponíveis na biblioteca, quanto à atualização?

53. A biblioteca de sua instituição oferece serviço de empréstimo de livros?

54. Como é o serviço de pesquisa bibliográfica oferecido?

55. A biblioteca tem um horário de funcionamento que atenda às suas necessidades?

56. Instalações para leitura e estudo?

B) Variáveis incluídas no Indice de Competências (o número corresponde ao item do questionário da Enade 2005):

75. Como você avalia os procedimentos de ensino adotados pela maioria dos professores quanto à adequação aos objetivos do curso?

80. Como é a disponibilidade dos professores do curso, na instituição, para orientação extraclasse?

81. Seus professores têm demonstrado domínio atualizado das disciplinas ministradas?

Em que medida o conjunto de disciplinas do curso contribui para você desenvolver as competências relacionadas abaixo:

94. Atuação ética, com responsabilidade social, para a construção de uma sociedade includente $\mathbf{e}$ solidária.

95. Organização, expressão e comunicação de pensamento.

96. Raciocínio lógico e análise crítica.

97. Compreensão de processos, tomada de decisão e resolução de problemas no âmbito de sua área de atuação.

98. Atuação em equipes multi, pluri e interdisciplinares.

99. Atuação profissional responsável em relação ao meio ambiente.

100. Observação, interpretação e análise de dados e informações.

101. Utilização de procedimentos de metodologia científica e de conhecimentos tecnológicos para a prática da profissão.

102. Utilização de recursos de informática necessários para o exercício profissional. 


\section{APÊNDICE 2}

\section{Modelo Analítico}

Modelo do Primeiro Nivel: estudantes de Pedagogia

Enade $=\beta 00+\beta 10^{*}($ IDADE $)+\beta 20^{*}($ RAÇA $)+\beta 30^{*}($ SEXO $)+\beta 40^{*}($ RENDA $)+\beta 50^{*}($ TC_EXP $)+r$

Modelo de Segundo Nível: cursos de Pedagogia

$\beta 00=\gamma 00+\gamma 01^{*}($ PÚBLICO $)+\gamma 02^{*}\left(\right.$ IN_REC) $+\gamma 03^{*}($ IN_COMP $)+\gamma 04^{*}($ REGIÃO)

$\beta 10=\gamma 10$

$\beta 20=\gamma 20$

$\beta 30=\gamma 30$

$\beta 40=\gamma 40$

$\beta 50=\gamma 50+\gamma 51 *($ PÚBLICO $)+\mathrm{U} 5$

$\beta 60=\gamma 60$

\section{Resultados}

\section{Nivel um: estudantes}

\begin{tabular}{lc}
\hline & Coeficiente \\
\hline Constante & $-0,077883$ \\
IDADE & $0,16264^{* * *}$ \\
SEXO & $-0,098432^{* *}$ \\
NÃO_BRAN & $-0,059003^{* *}$ \\
RF_3A10 & $0,283090^{* * *}$ \\
RF_M11 & $0,403604^{* * *}$ \\
EXP_MAG & $0,256328^{* * *}$ \\
\hline
\end{tabular}

Nível dois: cursos de Pedagogia

Efeitos Fixos

\begin{tabular}{lc}
\hline & Coeficiente \\
\hline RESULTADO & $-0,356508^{* * *}$ \\
SUMREC2 & $0,039586^{* *}$ \\
SUMCOMP2 & $-0,004392$ \\
PÚBLICO & $0,374849^{* * *}$ \\
SUL_SUDE & $0,277379^{* * *}$ \\
\hline
\end{tabular}

Efeitos Aleatórios

\begin{tabular}{lc}
\hline & Coeficiente \\
\hline EXP_MAG & $0,343810^{* * *}$ \\
PÚBLICO & $-0,355372^{* * *}$ \\
\hline
\end{tabular}

